SPECIAL ARTICLE

\title{
Leprosy in the Yemen Arab Republic
}

\author{
YASIN AL-QUBATI, ${ }^{*}$ H B OSTLER† \\ \& S K NOORDEEN $\ddagger$ \\ *Al-Gomhori and City of Light Hospitals, Taiz, Yemen Arah \\ Republic; $†$ Francis I. Proctor Foundation, University of California, \\ San Francisco, C A 94143; $\ddagger$ Leprosy Unit, World Health Organiza- \\ tion, Geneva, Switzerland
}

\section{Accepted for publication 29 March 1985}

\begin{abstract}
Summary The present situation with regard to leprosy control in the Yemen A rab Republic (North Yemen) is briefly reviewed. It is believed that there are currently about 1800 registered cases, of whom 1200 have active disease. The authors estimate that there are between 6000 and 8000 cases in the country. There is a 130bed hospital in Taiz, called the City of Light, which acts as a central leprosarium. Facilities for diagnosis and treatment are also available in other parts of North Yemen, but the overall situation with regard to the competence of health staff, laboratory facilities, chemotherapy, reactions, eye complications, deformities and rehabilitation is far from satisfactory. A plea is made for the appointment of a leprosy specialist and the urgent development of a national leprosy control programme, including the appropriate training of personnel.
\end{abstract}

\section{Introduction}

The Yemen Arab Republic (North Yemen) is located on the south-west edge of the Arabian Peninsula and has a population of about 8.6 million. It is bordered on the north by Saudi Arabia, on the west by the Red Sea, on the south and south-east by People's Democratic Republic of Yemen, (South Yemen), and the east by the Great Arabian desert. It encompasses about $200,000 \mathrm{~km} .^{2}$

Geographically, North Yemen can be conveniently divided into 4 divisions, each having its own characteristic altitude, climate, and vegetation. These divisions are: (1) the coastal lowlands of Tihama which stretch along the Red Sea from Saudi Arabia in the north to Bab-el Mandab in the south. Hodiedah, with a population of 120,000 , is the capital of this region; (2) the foothills and middle heights, at an altitude of 200-1500 m and situated between the Tihama and the central highlands; (3) the central highlands which exceed $1500 \mathrm{~m}$ in elevation and include Nabi Shu'ayb $(3760 \mathrm{~m})$, the highest mountain in North Yemen, Sana'a (population about 280,000), the capital of North Yemen, Taiz (population about 120,000), the second largest city in the country, and Ibb (population about 34,000), are all situated in the central highlands; (4) the eastern semi-desert 
plateau slopes gently eastward and drops to an elevation of $1000 \mathrm{~m}$ and borders the Empty Quartar, El-Rub El-Khali.

About 1.4 million of the population live and work outside the country. Much of what they earn is sent to their families in North Yemen and serves as a major source of income for the population there. Unlike Saudi Arabia to the north, there are no petroleum reserves in the Yemen Arab Republic. In 1980, the average annual per capita income was 2039 Rial (4.8 Rials less than $\$ 1 \cdot 00$ US).

The individual income of North Yemen is negatively affected by the widespread habit of chewing khat (Catha edulis), a green leaf plant cultivated on the mountain slopes. The social activity of chewing khat, the exhaustion following its use, and the cost of purchasing it, all serve to reduce the useful income of the population, especially as the coffee plant is no longer cultivated for export.

\section{Magnitude of the problem of leprosy in North Yemen}

Although progress in the care of patients with leprosy in North Yemen was at first slow, it has started to accelerate. Recently, the problem was evaluated by one of us (SKN) who visited North Yemen in the Spring of 1983 on behalf of the World Health Organization (WHO).

In the years from 1940 to 1960, patients were isolated and offered little medical care. In 1964, a sanatorium was built for leprosy patients, who were either hospitalized or given medication in the home. In the 1970s the sanatorium was improved, new wards were added, and it was named the City of Light. This facility is located in Taiz and is run by the Missionaries of Charity, a Catholic organization founded by Mother M. Teresa of Calcutta, India. There is a 130-bed hospital and homes for patients and their families who have been rejected by their community. Patients who are judged non-infectious are encouraged to return to their homes and occupations, but if they are rejected by their communities, they are allowed to live in the sanatorium where they are engaged in various occupations, including sewing for women, and farming, carpentry, stone cutting, building, and taxi-driving for men. There is a small dispensary which was used by one of us (HBO) for outpatient ophthalmic surgery, but general surgery or intra-ocular surgery is provided for the patients at the general hospital. Medical care is given by one of us (YA-Q), who attends the sanatorium twice weekly.

Although WHO recorded a figure of 850 registered cases in $1975,{ }^{\prime}$ information obtained from this visit suggested that a figure of 1800 is more accurate, with about 1200 suffering from active disease. It has recently been suggested ${ }^{2}$ that there may be as many as 18,000 cases of leprosy in the Yemen, but by reasonable estimates, admittedly based on limited data, our belief is that a total of $6000-8000$ is more likely. Unfortunately, there is marked social stigma against the disease. About one-half of the relatively high endemic governorates include Damar and Sana'a located in the central highlands, and Hodeidah, located in the coastal lowland of Tihama. The disease is relatively uncommon among children.

Facilities for treatment are available in Al-Hudahdah and in Jeblah (in the central highlands) and in Damar. The treatment offered in these areas, however, is not well organized and only minimal facilities for skin-smear examination and treatment of complications are available. This is also true for the sanatorium. Furthermore, there are no mobile teams for the early detection and treatment of the disease. There are no qualified physiotherapists, nor is there physiotherapy equipment for the treatment of the handicapped patients, although minimal international collaboration for patient care and research work is now available.

\section{Conclusions and recommendations}

There is an important need for an individual interested in leprosy to be appointed at the Ministry of Health to ensure full teamwork in the problem. Under this person's direction, a national plan for the 
control of leprosy should be prepared. The plan should include means of carly identification and early treatment of patients, follow-up on treatment, prevention of deformities, and the rehabilitation of patients with deformities. Mobile teams for case detection which would work first in the highly endemic areas, and later in the other areas, should be mobilized. Members of the community should be educated so that they can help in the early detection and assist in preventing social rejection. Personnel should be trained in physiotherapy for prevention of deformities and the rehabilitation of patients with deformities. Laboratory personnel should be trained in the preparation and examination of smears for the identification of acid-fast organisms. The sanatorium at Taiz (the City of Light) should be upgraded to serve as the national hospital training centre for the medical and paramedical personnel. (Initially, the training of personnel who would work at the City of Light could be arranged at the All Africa Leprosy and Rehabilitation Training Centre (ALERT) in Addis Ababa.) Leprosy should be part of the curriculum of the new medical school being built at Sana'a and in the Health Manpower School at Sana'a. International collaboration and consultation should be sought to help in training personnel, research, and for financial support of these programmes.

To accomplish these goals, an international consultant(s) should be sought to help ensure sound policies and to help implement the programmes. Financial support for equipment, personnel, and patient care should be obtained from international organizations. The mobile teams which are formed should be attached to regional hospitals where adequate facilities for diagnosis, laboratory examination, and the treatment of complications can be handled. Combined chemotherapy, as recommended by the WHO study group on Chemotherapy of Leprosy for Control Programmes, ${ }^{3}$ should be implemented as soon as reasonably possible. In order that this can be accomplished safely and effectively, a high priority must now be given to leprosy work generally, both in the training of health personnel and laboratory technicians, in upgrading the City of Light and in the development of physiotherapy for the prevention of deformity and the care of the deformed.

\section{References}

1 WHO. LEPROSY (LEPRE). WHO Wkly Epidem Rec, 1979; 3: 17-23.

${ }^{2}$ Lavrik AU. Features of leprosy epidemiology in the Yemen Arab Republic. Vestn Dermatol Venerol, 1983; 4: 46-9.

3 WHO. Chemotherapy of leprosy for control programmes. Report of a WHO Study Group. Technical Report Series 675. WHO, Geneva (1982). 